\title{
X-Ray Fluorescence Microtomography in Biological Applications
}

\author{
Gabriela R. Pereira ${ }^{1}$ and Ricardo T. Lopes ${ }^{2}$ \\ ${ }^{1}$ Non-destructive Testing, Corrosion and Welding Laboratory, \\ Department of Metallurgical and Materials Engineering COPPE/UFRJ \\ Federal University of Rio de Janeiro, Rio de Janeiro/RJ \\ ${ }^{2}$ Nuclear Instrumentation Laboratory, Department of Nuclear Engineering \\ COPPE/UFRJ, Federal University of Rio de Janeiro, Rio de Janeiro/RJ \\ Brazil
}

\section{Introduction}

Since tomographic techniques were developed, X-ray transmission tomography has been used in nondestructive testing for investigating the internal structure of samples, and with the advent of intense synchrotron radiation sources the resolution of the tomography was improved into $\mu \mathrm{m}$ regime.

Other complementary tomographic techniques have been developed based on the detection of the scattered (Golosio et al., 2003) and fluorescent photons (Cesareo \& Mascarenhas, 1989.) in other to get some properties that also depend upon the distribution of individual elements within the sample. The X-ray fluorescence associate with tomographic techniques can supply important information of the sample chemical properties and to produce high contrast in conditions where transmission tomography is not adjusted.

One of the drawbacks of X-ray fluorescence tomography is the reconstruction calculation that is more complex than X-ray transmission tomography's algorithm (Hogan et al., 1991). Hogan et al. proposed adapting one of the algorithms used in X-ray transmission tomography (Brunetti \& Golosio, 2001). The simplest algorithm is based on the classical back projection algorithm used In X-ray transmission tomography. An algorithm more accurate applies corrections for absorption before and after the fluorescence point.

In recent years, there has been growing interest in understanding the exact role played by trace elements in several diseases. The biological function of some metal ions in combination with an investigation of element distribution patterns in malignant and in normal human tissues of cancer patients can give some indication of the effect of metal ions on carcinogenesis (Raju et al., 2006). Both excess and deficiency of trace elements have been associated with many diseases including cancer. Even though extensive work has been carried out to find an association between trace elements and cancer, and to understand the mechanisms involved in carcinogenesis, no definite conclusions are drawn so far (Rocha et al., 2007).

Although trace elements $\mathrm{Fe}, \mathrm{Cu}$, and $\mathrm{Zn}$ are extremely common, assessment of their amounts is crucial for disease diagnostics. Both excess and deficiency of trace elements have 
been associated with many diseases including cancer (Pereira et al., 2010). Iron, copper and zinc can not only be associated with functions that protect the body against to illness, but also with processes that facilitate its propagation.

Copper acts as catalytic for enzymes that have to defend the human organisms. In the other hand, the copper can act as catalyst for production of hydroxyl radicals that are related with cells destruction.

Changes in the concentration of iron must be associates to the vascularization and the increase of the supplement of blood for the tumors growth. Moreover, the iron is an essential element for the organism because it is part integrant of some proteins. The iron influences the process of cancer because it plays a vital role in the regulation of the cells growth and its differentiation (Pereira et al., 2008).

Zinc participates of many reactions in cellular metabolism including physiological processes, such as immune function, growth and development, acting as a structural and functional component of many enzymes and proteins. Studies show that the prostate has the capacity to secrete high zinc level and that the concentration of this metal it is directly related to the prostate cancer, therefore a deepened study on the behavior of zinc in the prostate it makes necessary.

X-ray fluorescence microtomography technique has enabled us to determine the elemental distribution of the elements inside of the sample without destructed it. It is a useful tool in qualitative and quantitative analysis of biological tissues (Pereira et al., 2010). The great advantage of this technique is the visualization in tree-dimension of the elemental distribution without material damages.

\section{X-ray fluorescence microtomography}

X-ray transmission computed tomography is a well established diagnostic technique in Medicine. It is a non-destructive testing and allows reconstructing the image of the crosssections of a sample starting from a set of X-ray "radiographic" measurements taken at different angles. It is performed by placing an X-ray source and an X-ray detector aligned at opposite sides of the sample. The detector records the part of the radiation emitted by the $X-$ ray source that crosses the sample without interacting with it. The reconstructed image represents a map of the cross section in terms of linear attenuation coefficient of the material, which is a function of the mean atomic number $(\mathrm{Z})$ and density in each single volume element (voxel) (Pereira et al., 2009).

$\mathrm{X}$-ray fluorescence tomography is based on detection of photons from fluorescence emission from the elements in the sample. These photons are acquired by an energy dispersive detector, placed at $90^{\circ}$ to the incident beam direction, and they are used as additional information for sample characterization. Figure 1 shows a schematic diagram of X-Ray Fluorescence Tomography.

According to Hogan et al. 1991, the X-ray fluorescence radiation at each point in the sample can be obtained through the following equations.

For a particular element $i$ and an atomic level $v$, the fluorescence radiation hitting the energy dispersive detector can be obtained through integration along the path du:

$$
I_{i v}(\theta, s)=I_{0} \int_{-\infty}^{\infty} d u f(\theta, s, u) p(s, u) g(\theta, s, u)
$$




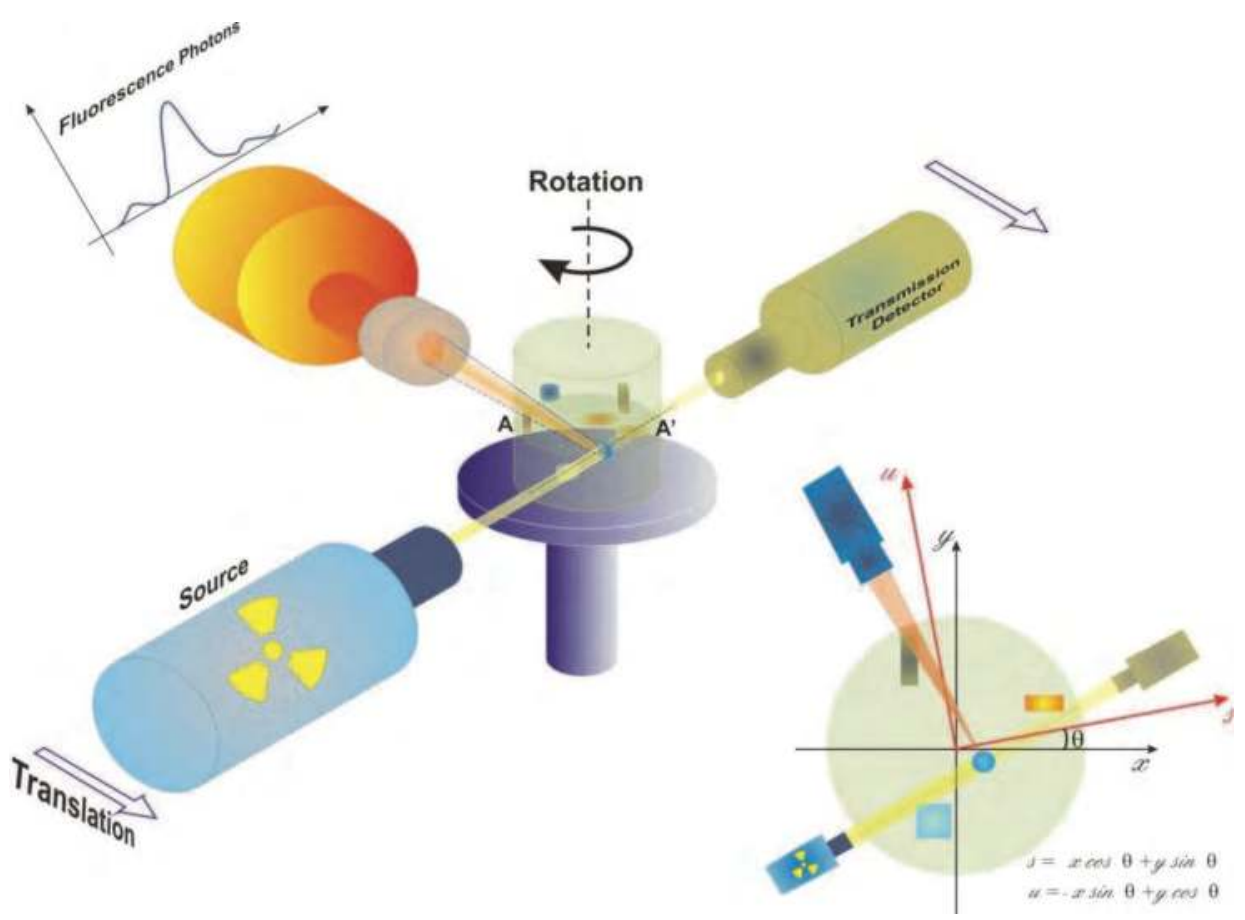

Fig. 1. Schematic diagram of X-ray fluorescence tomography.

where $\mathrm{I}_{0}$ is the intensity of the incident beam; $f$ is the survival probability of a photon from the source to the point $(\mathrm{s}, \mathrm{u})$, which is related to the sample absorption coefficient, $\mu_{\mathrm{B}}$, at the beam energy:

$$
f(\theta, s, u)=e^{-\int_{-\infty}^{u} d u^{\prime} \mu_{B}\left(s, u^{\prime}\right)}
$$

and $g$ is the probability that a fluoresce photon emitted from the point $(s, u)$ reaches the detector:

$$
g(\theta, s, u)=\frac{1}{4 \pi} \int_{\Omega_{D}} d \Omega \exp \left(-\int_{s, u}^{D e t} \mu_{F}(l) d l\right)
$$

where $\mu_{\mathrm{F}}$ is the absorption coefficient of the sample at the fluorescence energy and $\Omega_{\mathrm{D}}$ is the solid angle from the fluorescence point to the detector surface.

The function $\mathrm{p}$ is the probability that a fluorescence photon is produced from an incident photon along the path du:

$$
p(s, u) d u \propto N_{\text {elem }}
$$

where, the concentration of the element at the point $(s, u)$ is Nelem. If the solid angle defined by the detector surface is almost constant and the attenuation is small $\left(\mu_{\mathrm{B}} \approx \mu_{\mathrm{F}} \approx 0\right)$ then: 


$$
I_{i v}(\theta, s) \propto I_{0} \int_{-\infty}^{\infty} d u N_{e l e m}
$$

That means that the concentration of the element is proportional to the experimental projections and the usual algorithms of X-ray transmission tomography (Kak et al., 1988) can be used for reconstructed the images of X-ray fluorescence tomography. Otherwise, beam attenuation must be taken into account and new algorithms for tomographic reconstruction are indispensable (Brunetti \& Golosio, 2001)

Self-absorption corrections are described below and it were implement in the Brunetti \& Golosio 2001 algorithm. The algorithm is divided into two stages: MKCORR (that generates the matrix correction) and SCTOMO (backprojection algorithm).

Approximating the integral over du with a discrete sum, Eq. (1) can be expressed as

$$
I(\theta, s)=\sum_{u=-\infty}^{+\infty} I_{0} f(\theta, s, u) p(s, u) g(\theta, s, u) d u
$$

Following Hogan et al. 2001 it can be considering the total count, i.e. the sum of the counts from all those beam directions passing through the point $\left(\mathrm{s}_{0}, \mathrm{u}_{0}\right)$

$$
I_{\text {total }}\left(s_{0}, u_{0}\right)=I\left(\theta_{1}, s_{1}\right)+I\left(\theta_{2}, s_{2}\right)+\ldots+I\left(\theta_{n}, s_{n}\right)
$$

with can be expanded in terms of $\mathrm{p}$ and of the absorption factors $\mathrm{f}$ and $\mathrm{g}$ as:

$$
\begin{aligned}
I_{\text {total }}\left(s_{0}, u_{0}\right)= & \sum_{u_{1}} I_{0} f\left(\theta_{1}, s_{1}, u_{1}\right) p\left(s_{1}, u_{1}\right) g\left(\theta_{1}, s_{1}, u_{1}\right) \\
& +\sum_{u_{2}} I_{0} f\left(\theta_{2}, s_{2}, u_{2}\right) p\left(s_{2}, u_{2}\right) g\left(\theta_{2}, s_{2}, u_{2}\right) \\
& +\ldots+\sum_{u_{n}} I_{0} f\left(\theta_{n}, s_{n}, u_{n}\right) p\left(s_{n}, u_{n}\right) g\left(\theta_{n}, s_{n}, u_{n}\right) .
\end{aligned}
$$

Separating, in this sum, the contribution due to the point $\left(\mathrm{s}_{0}, \mathrm{u}_{0}\right)$ :

$$
\begin{aligned}
I_{\text {total }}\left(s_{0}, u_{0}\right)= & I_{0} f_{0}\left(\theta_{1}, s_{1}, u_{1}\right) p\left(s_{0}, u_{0}\right) g_{0}\left(\theta_{1}, s_{1}, u_{1}\right) \\
& +I_{0} f_{0}\left(\theta_{2}, s_{2}, u_{2}\right) p\left(s_{2}, u_{2}\right) g_{0}\left(\theta_{2}, s_{2}, u_{2}\right) \\
& +\ldots+I_{0} f_{0}\left(\theta_{n}, s_{n}, u_{n}\right) p\left(s_{n}, u_{n}\right) g_{0}\left(\theta_{n}, s_{n}, u_{n}\right) \\
& +\sum_{u_{1} \neq u_{0}} I_{0} f\left(\theta_{1}, s_{1}, u_{1}\right) p\left(s_{1}, u_{1}\right) g\left(\theta_{1}, s_{1}, u_{1}\right) \\
& +\sum_{u_{2} \neq u_{0}} I_{0} f\left(\theta_{2}, s_{2}, u_{2}\right) p\left(s_{2}, u_{2}\right) g\left(\theta_{2}, s_{2}, u_{2}\right) \\
& +\ldots+\sum_{u_{n} \neq u_{0}} I_{0} f\left(\theta_{n}, s_{n}, u_{n}\right) p\left(s_{n}, u_{n}\right) g\left(\theta_{n}, s_{n}, u_{n}\right) .
\end{aligned}
$$

where the subscripts zero on $\mathrm{f}$ and $\mathrm{g}$ signify the appropriate absorption factors for the point $\left(\mathrm{s}_{0}, \mathrm{u}_{0}\right)$. Solving for $\mathrm{p}\left(\mathrm{s}_{0}, \mathrm{u}_{0}\right)$, Eq. (9) yields: 


$$
\left.p\left(s_{0}, u_{0}\right)=\frac{I_{\text {total }}\left(s_{0}, u_{0}\right)}{I_{0} \sum_{i=1}^{n} f_{0}\left(\theta_{i}, s_{i}, u_{i}\right) g_{0}\left(\theta_{i}, s_{i}, u_{i}\right)}+\sum \text { (outros termos }\right) .
$$

According to Hogan, the "other terms" are noise that can be regarded as an artifact of backprojection. Such noise can thus be removed by convolution of the projections with a filter suitable for backprojection. Therefore $\mathrm{p}\left(\mathrm{s}_{0}, \mathrm{u}_{0}\right)$ can be approximated as

$$
p\left(s_{0}, u_{0}\right)=\frac{\tilde{I}_{\text {total }}\left(s_{0}, u_{0}\right)}{I_{0} \sum_{i=1}^{n} f_{0}\left(\theta_{i}, s_{i}, u_{i}\right) g_{0}\left(\theta_{i}, s_{i}, u_{i}\right)},
$$

where the tilde above $\mathrm{I}_{\text {total }}$ represents the operation of filterd backprojection.

A common approach is to determine the absorption coefficient distribution $\mu_{\mathrm{B}}$ and $\mu_{\mathrm{F}}$ using two conventional transmission tomographies.

\section{Crystal monochromator}

Multilayer crystals are part of a new generation of optical components based on X-ray diffraction of synthetic crystals.

Sometimes referred to as layered synthetic microstructures (LSM) or simply as multilayers, these optical components consist of layered depositions of materials A and B, having a significant difference in their indices of refraction. Most commonly, $\mathrm{n}$ layer pairs are fabricated to form a structure of uniform period by depositing alternating thin layers on top of smooth substrate. Material A is low-Z material such as carbon or silicon and B is a high-Z material such as tungsten or platinum. The efficiency of diffraction can be as high as 50 to $80 \%$ over bandwidths of 0.005 to 0.1 , making feasible a new class of high-power, large bandwidth X-ray optics (Ebashi et al., 1991).

The performance of multilayer crystals are mainly influenced by the refractive index of materials and the number and thickness of individual layers.

The Figure 2 shows the reflectivity curve from a crystal monochromator made of tungsten and carbon $(\mathrm{W}-\mathrm{C})$ and it has 75 layer pairs, $\Delta \mathrm{E} / \mathrm{E}=0,03$.

\section{Sample preparation}

The main advantage of $\mathrm{X}$-ray Fluorescence Microtomography $(\mathrm{XRF} \mu \mathrm{CT})$ resides in being a non-destructive technique, allowing the use of the same sample for further characterization with other kind of techniques like X-ray diffraction (Rocha et al., 2007). In comparison with conventional micro $\mathrm{X}$-ray fluorescence analysis, the $\mathrm{XRF} \mu \mathrm{CT}$ does not require any sample preparation such as embedding or fixing the samples in paraffin to get an ultrafine and accurate slices (approximately 15 microns). The $\mathrm{XRF} \mu \mathrm{CT}$ does not require this kind of sample preparation; it is not necessary to cut the sample to analyze the tomographic plane. It is possible to analyze small samples without destroying them, biopsies for example. It is not necessary frozen and dried the samples. Sometimes, the samples can be frozen and dried before being analyzed to reduce the attenuation of X-ray fluorescence and the measurement time in biological samples, for example. 


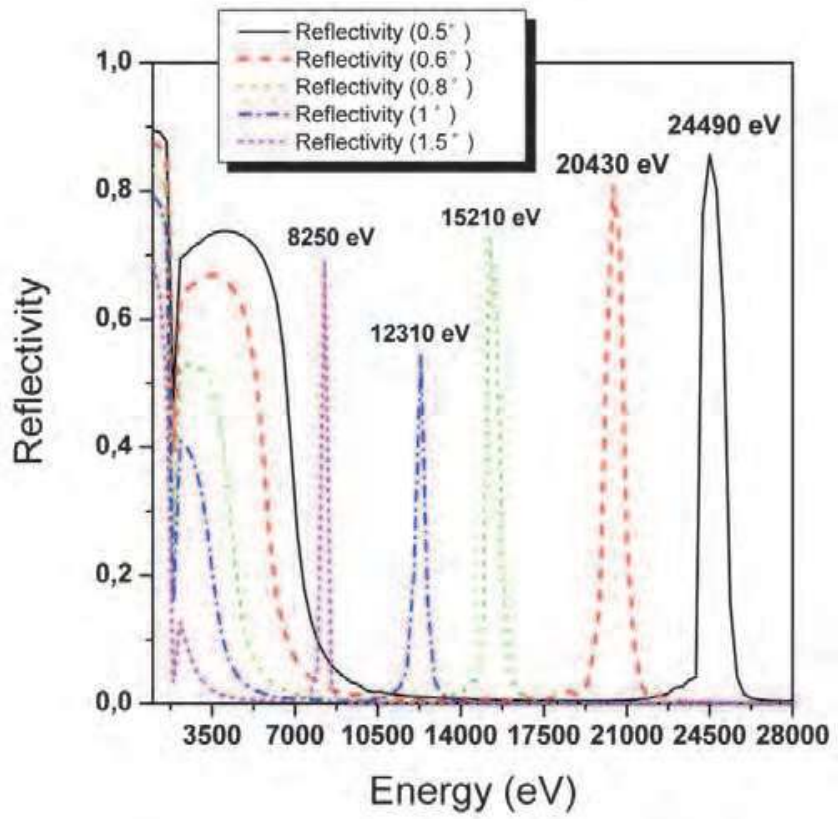

Fig. 2. Reflectivity curve.

\section{Methods}

There are many methods that can be implement to develop X-ray fluorescence microtomography. It can be use conventional X-ray tube, synchrotron radiation, X-ray microfocus and other sources. Also in many cases it is used a confocal geometry.

The excellent properties of synchrotron radiation sources, such as the possibility of setting a specific energy (monochromatic beam); high coherency beam; high photon flux; broad energy spectrum and natural collimation allow the use of X-ray fluorescence microtomography techniques. The use of synchrotron radiation reduces a lot the acquisition time and the noise in X-ray fluorescence images.

It will be present a development of a system to study X-ray fluorescence microtomography at the X-Ray Fluorescence Facility (D09B-XRF) at the Brazilian Synchrotron Light Laboratory (LNLS), Campinas, Brazil. A white beam (4-23 keV), a monochromatic beam produced by a $\mathrm{Si}$ (111) at $9.8 \mathrm{keV}$ and a quasi-monochromatic beam produced by a multilayer monochromator at $12 \mathrm{keV}, \Delta \mathrm{E} / \mathrm{E}=0.03$ collimated to a $200 \times 200 \mu \mathrm{m}^{2}$ area with a set of slits, were used to sample excitation. The crystal multilayer monochromator is made of $\mathrm{W}-\mathrm{C}$ and it has 75 layer pairs.

The intensity of the incident beam was monitored with an ionization chamber placed in front of it, before the sample. A schematic of the experimental setup for an X-ray fluorescence microtomography using a multilayer monochromatic beam is shown in Figure 3. The setup using white beam is the same setup of figure 3 but without the multilayer crystal and to obtain the monochromatic setup we change the multilayer system by two crystal of $\mathrm{Si}(111)$. 


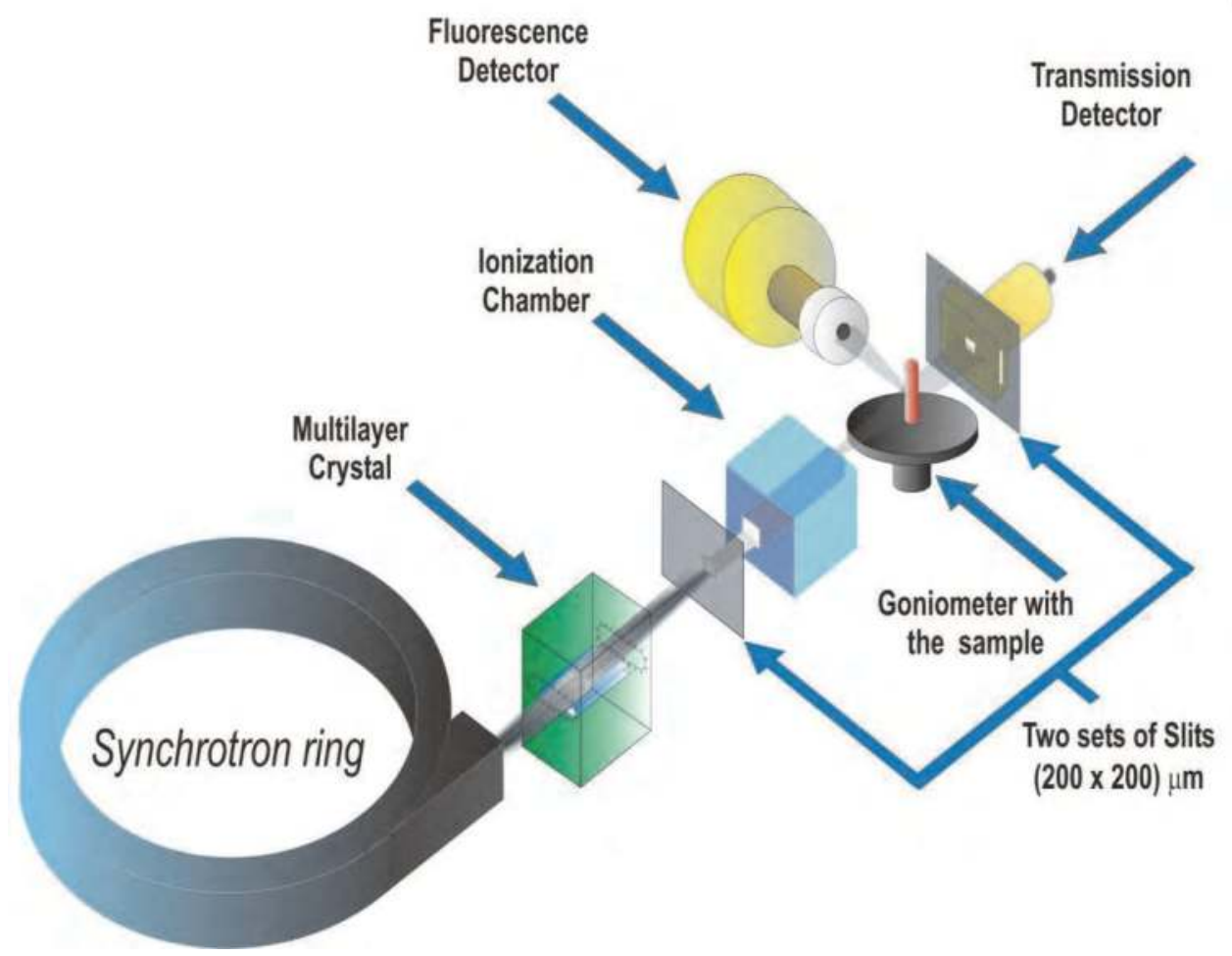

Fig. 3. The experimental arrangement for an X-ray fluorescence microtomography measurement using a multilayer monochromator beam.

The sample was placed on a high precision goniometer and translation stages that allow rotating as well as translating it perpendicularly to the beam. The fluorescence photons were collected with an energy dispersive HPGe detector placed at $90^{\circ}$ to the incident beam, while transmitted photons were detected with a fast $\mathrm{NaI}$ (Tl) scintillation counter placed behind the sample on the beam direction. This detector geometry allows reducing the elastic and Compton X-ray scattering from the sample due to the high linear polarization of the incoming beam in the plane of the storage ring, thus improving the signal to background ratio for the detection of trace elements (Naghedolfeizi et al., 2003).

The quality of the reconstruction is a compromise between the measuring time required for an acceptable counting statistic of the X-ray fluorescence peaks and the step size necessary to linearly move and rotate the samples. In one projection, samples were positioned in steps of $200 \mu \mathrm{m}$ (actual beam size) perpendicularly to the beam direction covering the whole transversal section of the sample proof. The number of translations was about 20 according to the sample.

Each single value in a projection is obtained by measuring the fluorescence radiation emitted by all pixels along the beam. The object is then rotated, and another projection is measured. Projections are obtained in steps of $3^{\circ}$ until the object has completed $180^{\circ}$. The number of rotations was 60 . The selected measuring time was about $10 \mathrm{~s}$ for each scanned point according to the sample. 


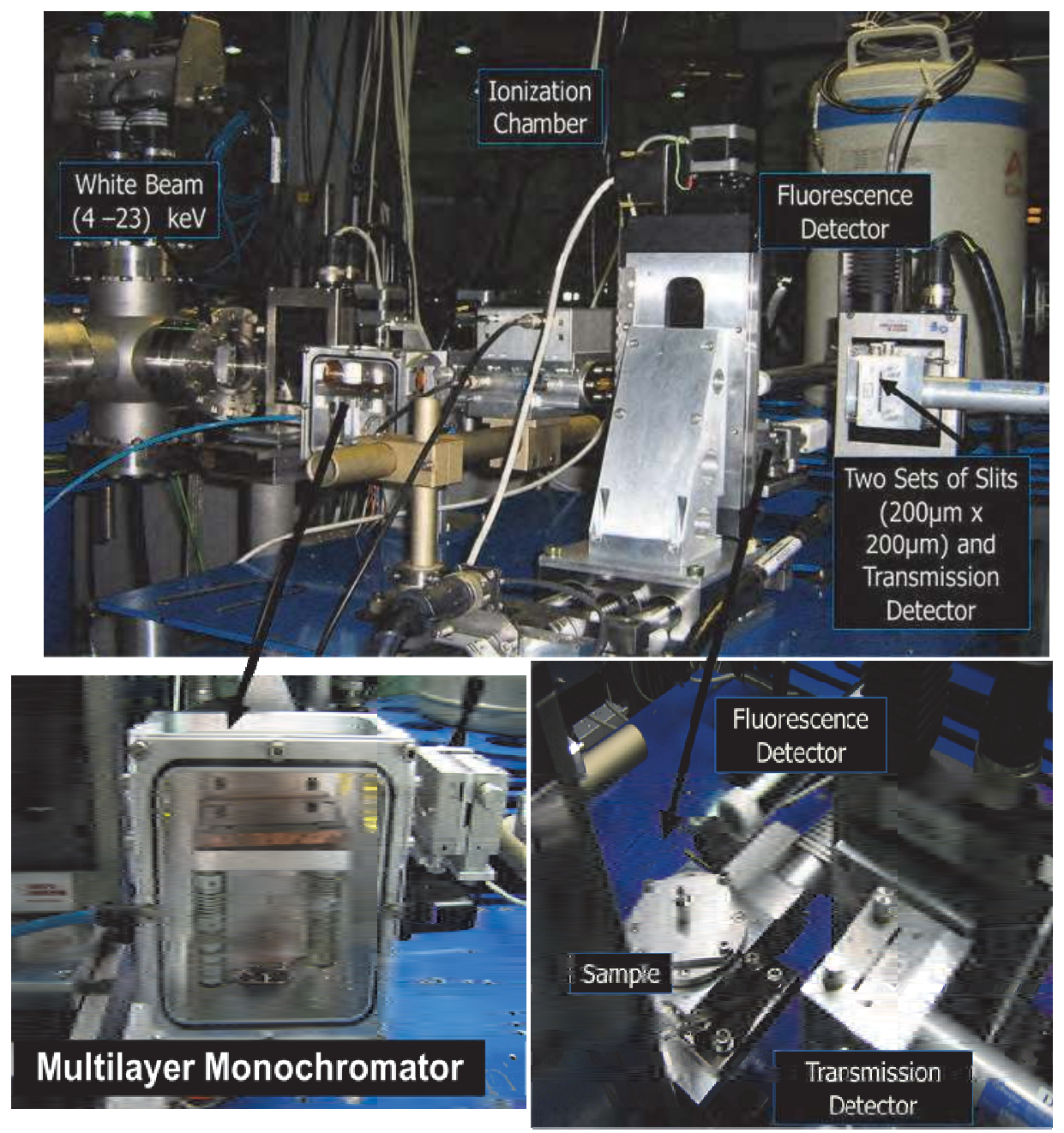

Fig. 4. A photo of an X-ray fluorescence microtomography measurement using a multilayer monochromator beam at LNLS/Brazil.

A reference sample made of filter paper was first analyzed and used as a test sample. One piece of the filter was impregnated with a solution containing $500 \mathrm{ppm}$ of zinc while the other remained untouched. Both pieces of filter paper were rolled up until it reached a cylindrical shape. The filter paper thickness was approximately $130 \mu \mathrm{m}$.

Another reference sample mades of polyethylene filled with a standard solution of copper was analyzed and used as a test sample too. That reference sample is made of a polyethylene cylinder with two millimeters diameter with an internal cylinder with one millimeter diameter filled a standard solution of copper, 100 parts per million (100 ppm).

As a second part of the experiments, $X$-ray fluorescence microtomographies were performed on human breast, lung and prostate tissue samples. The component tissues were identified 
by the pathologist who made the sample available. The tissues were cut in cylindrical form with $1.5 \mathrm{~mm}$ to $2.0 \mathrm{~mm}$ thickness by $4.0 \mathrm{~mm}$ to $5.0 \mathrm{~mm}$ of height and were frozen and dried before being analyzed.

The Figure 4 shows a photograph of the experimental setup for an X-ray fluorescence microtomography measurement using a multilayer monochromator beam. .

After the data from X-ray fluorescence microtomography were obtained, the spectra were analyzed using the software QXAS (Quantitative X-ray Analysis System)(Bernasconi et al,1996). The QXAS makes the analysis of the X-ray fluorescence peaks and generates an output file with all the intensity of X-ray fluorescence for each element in each point in the sample.

The X-ray transmission and the X-ray fluorescence images were reconstructed using a inhouse program developed using MATLAB® applying filtered-back projection algorithm. The absorption corrected matrix was obtained using MKCORR, a program developed by Brunetti \& Golosio, 2001. The 3D images were reconstructed using the 3D-DOCTOR software.

\section{Results and discussion}

The X-ray transmission and X-ray fluorescence microtomography of test samples are shown in Fig. 5-8. In Figure 5, it can be observed that while X-ray transmission microtomography shows all layers of the filter paper, $\mathrm{X}$-ray fluorescence microtomography shows only those regions where the element of interest $(\mathrm{Zn})$ was localized. These tomographies show the viability of $\mathrm{XRF} \mu \mathrm{CT}$ and confirm that this technique can be used to complement other techniques for sample characterization.
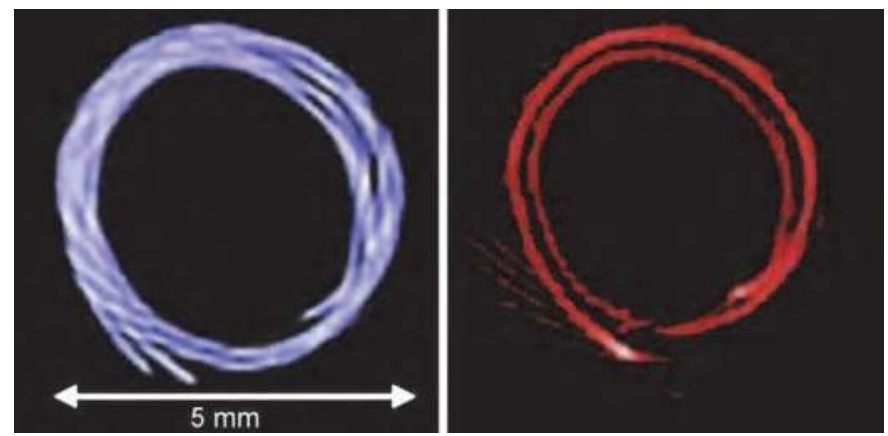

Fig. 5. Tomography images of paper filter (left: transmission and right: X-rayfluorescence).

The results for the test samples made of a polyethylene are shown in Figures 6-8. Analyzing the images it can be seen that the X-ray transmission images show the polyethylene matrix and the internal cylinder while the X-ray fluorescence images show only those regions where the elements of interest (copper) were localized. The results for the test samples made of polyethylene using a white beam, a monochromatic beam at $9.8 \mathrm{keV}$ and a quasimonochromatic beam at $12 \mathrm{keV}$ are shown in Figure 6, 7 and 8, respectively.

In the figures, the left image shows the $\mathrm{X}$-ray transmission microtomography and the right shows the X-ray fluorescence microtomography of copper reconstructed with filtered-back projection algorithm without absorption corrections. These tomographies show the viability 
of X-ray fluorescence microtomography and confirm that this technique can be used to complement others techniques for sample characterization.

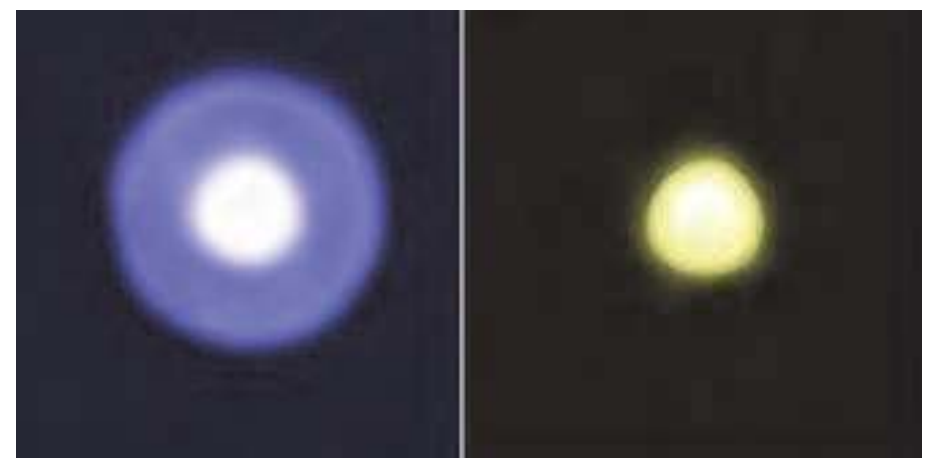

Fig. 6. Tomographic images using a white beam (left: Transmission microtomography; right: X-ray fluorescence microtomography of $\mathrm{Cu}$ ).
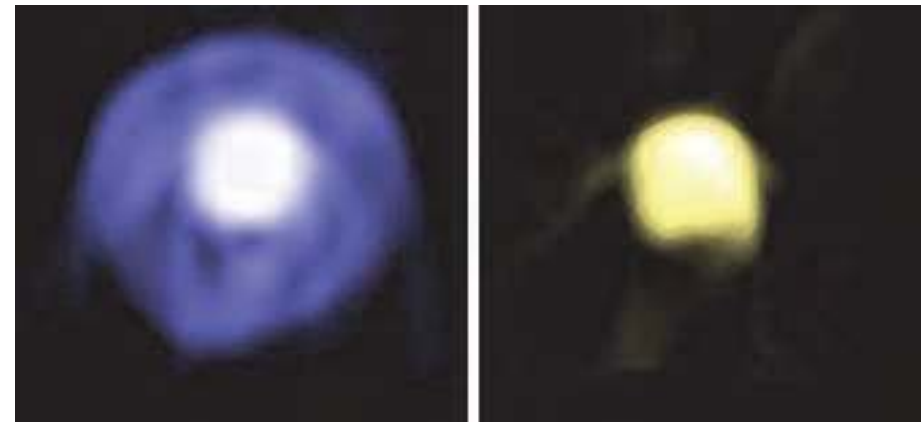

Fig. 7. Tomographic images using a monochromatic beam at $9.8 \mathrm{keV}$ (left: Transmission microtomography; right: X-ray fluorescence microtomography of $\mathrm{Cu}$ ).
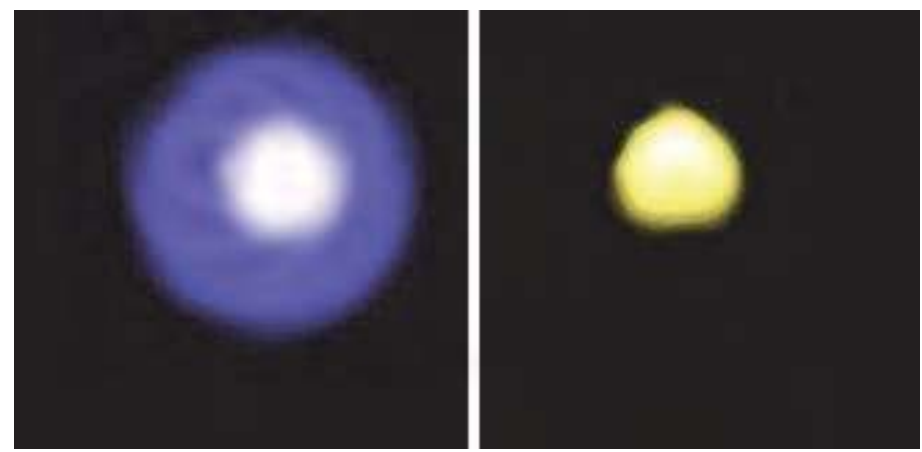

Fig. 8. Tomographic images using a quasi-monochromatic beam at $12 \mathrm{keV}$ (left: Transmission microtomography; right: X-ray fluorescence microtomography of $\mathrm{Cu}$ ). 
Analyzing the test samples images, it can be observed that the images do not have differences; the images have the same characteristics. The biggest advantage of the analysis with a monochromatic beam or quasi-monochromatic beam is the possibility to determine the attenuation coefficients for the fluorescence energy and for beam energy and with these coefficients make the absorptions corrections and accurately determining the concentration in each point of the sample. The advantage of the quasi-monochromatic beam at $12 \mathrm{keV}$ is the bigger photon flux than the monochromatic beam at $9.8 \mathrm{keV}$. Using a quasimonochromatic beam at $12 \mathrm{keV}$, with lesser time it could be obtained an image with a better statistic value and lesser radial artefacts.

The results that will be presented are part of a study about elemental distribution and concentration of iron, copper and zinc in breast, lung and prostate samples.

Before the tissues tomographic measurements were initiated, the X-ray beam was centered on each tissue sample to determine the detectable trace elements. The measured fluorescence spectrum from a breast cancer sample is shown in Figure 9.

X-ray fluorescence microtomographies were performed on prostate tissue, human breast, embryo lung and adult lung samples and the results can be shown in Figures 10, 11, 12, 13, 14 and 15.

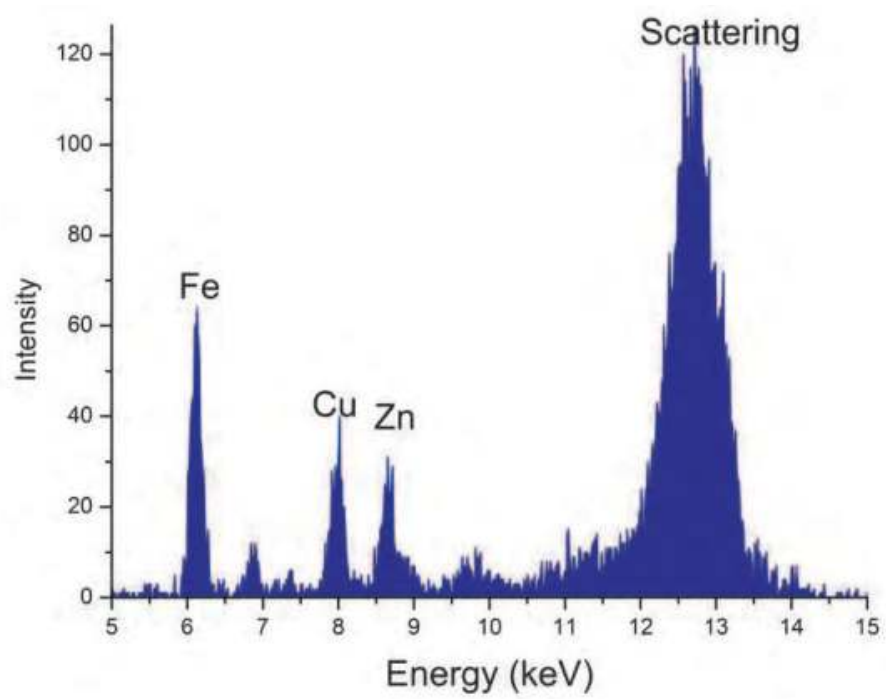

Fig. 9. An X-ray fluorescence spectrum from the breast cancer sample.

X-ray fluorescence microtomographies were performed on human prostate tissue samples. It was analyzed three prostate samples with BPH for tree different patients.

The result for human prostate samples is shown in Figure 10. Each line in the Figure 10 shows the $\mathrm{X}$-ray transmission microtomography and the $\mathrm{X}$-ray fluorescence microtomographies of $\mathrm{Fe}, \mathrm{Cu}$ and $\mathrm{Zn}$ with absorption corrections for each prostate tissue.

Analyzing the X-ray fluorescence microtomographies of human prostate tissue sample fragments, it was possible to see the elemental distribution of iron, copper and zinc. It was verified that these tissues have a less concentration of copper and iron than zinc and the mean concentration of zinc in the BPH samples is about 150 to $300 \mu \mathrm{g} / \mathrm{g}$. 
In Figure $10 \mathrm{f}$ it can be seen that there is a flaw in the iron X-ray fluorescence distribution image. There is not iron in the entire sample.

Figure 11 also shows the 3D images of a prostate sample with Benign Prostatic Hyperplasia (BPH). It was not possible reconstruct the 3D X-ray Fluorescence Microtomography (XRF $\mu \mathrm{CT}$ ) copper because the concentration of this element in that sample are very small, less than $3 \mu \mathrm{g} / \mathrm{g}$.

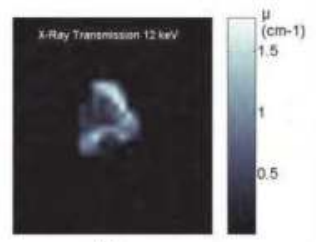

(a)

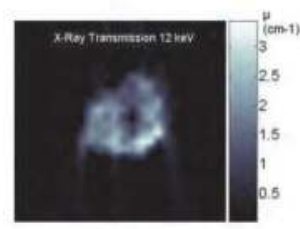

(e)

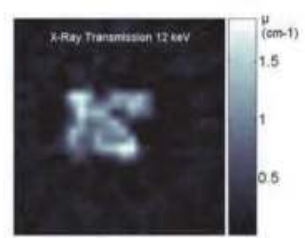

(i)

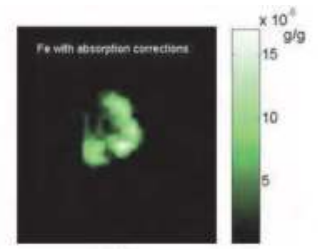

(b)

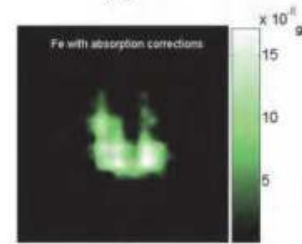

(f)

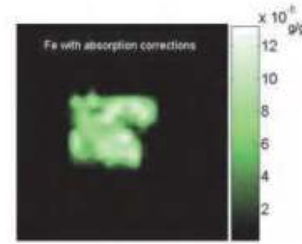

(j)

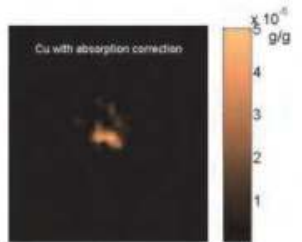

(c)

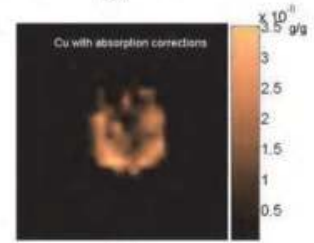

(g)

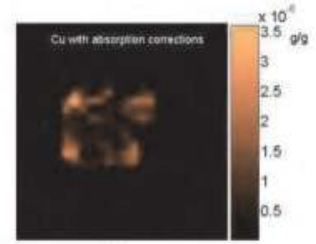

(k)

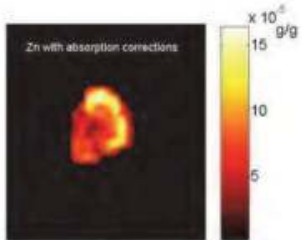

(d)

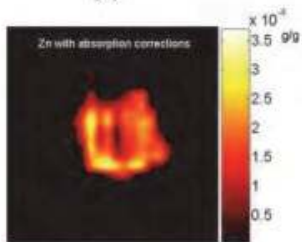

(h)

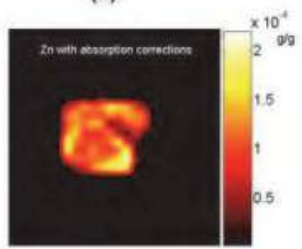

(I)

Fig. 10. X-ray transmission microtomographies and XRF microtomographies of iron, copper and zinc in human prostate BPH samples.
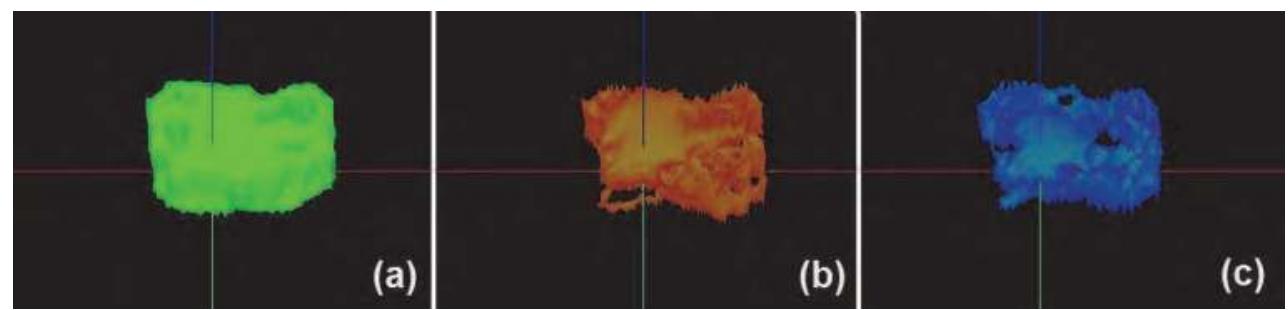

Fig. 11. 3D Tomographic images of a prostate sample with Benign Prostatic Hyperplasia (BPH), (a) CT, (b) XRF $\mu \mathrm{CT}$ of iron, (c) XRF $\mu \mathrm{CT}$ of zinc.

X-ray fluorescence microtomographies were performed on human breast tissue samples. Malignant breast tumor (ductal carcinoma) and healthy tissues were analyzed for the same patient. The component tissues were identified by the pathologist who made the sample available. The result for a breast samples are shown in Figure 12. In the first line at Figure 12 
it can be seen the results for a cancer sample and the second one, it can be observed the results for a healthy breast tissue sample.

Analyzing the images, it can be observed that the two samples have a bigger concentration of iron comparing with the concentration of copper and zinc and for this patient; the concentration of iron and zinc is bigger in the cancer sample than in the healthy sample.

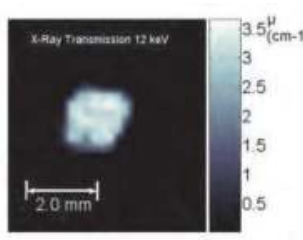

(a)

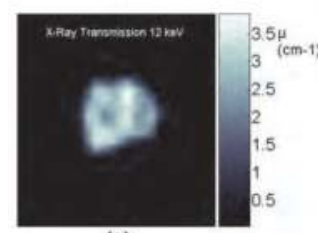

(e)

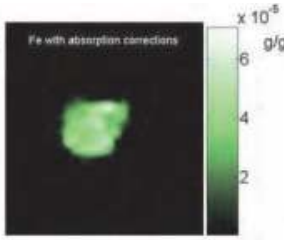

(b)

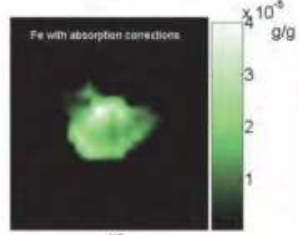

(f)

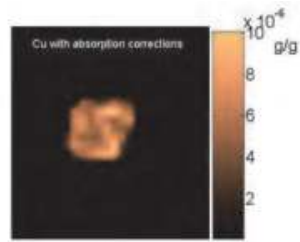

(c)

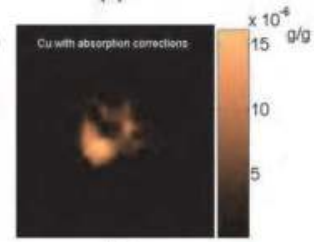

(g)

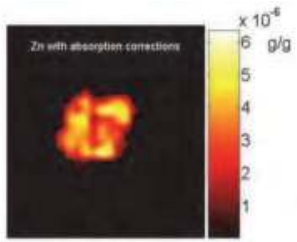

(d)

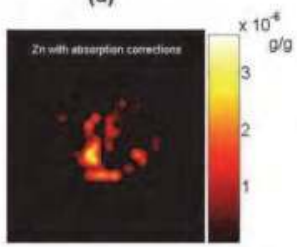

(h)

Fig. 12. X-ray transmission microtomographies and X-ray fluorescence microtomographies of iron, copper and zinc in human breast tissue samples.

The mean concentration of iron is about $50 \mu \mathrm{g} / \mathrm{g}$, for copper the mean concentration is about $6 \mu \mathrm{g} / \mathrm{g}$ and for zinc is about $7 \mu \mathrm{g} / \mathrm{g}$ in healthy tissue. Comparing these mean values for healthy tissue with the mean values for cancer tissue for the same patient, it can be seen that for iron the mean value is forty percent greater in cancer sample, for copper there is no significant difference and for zinc the mean concentration doubling in cancer sample. These results are in accordance with the literature (Geraki et al., 2004). But it is necessary to measure more samples and quantify the difference in concentration in one sample and between normal and abnormal tissues to use the X-ray fluorescence microtomography as an analytic tool to analyze biological tissues.
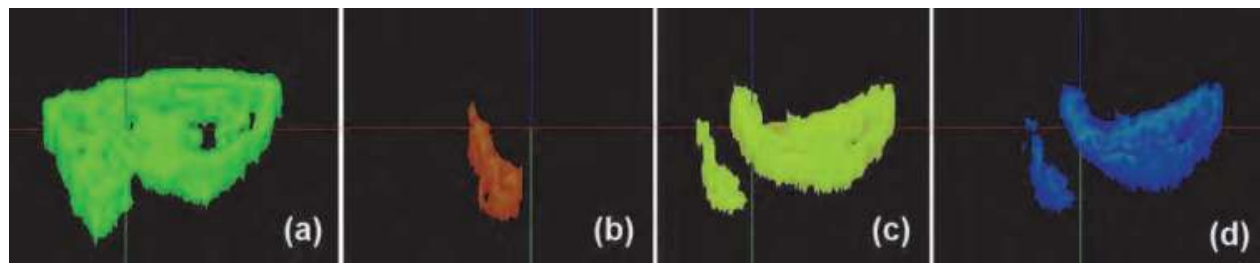

Fig. 13. 3D Tomographic images of healthy breast sample, (a) CT, (b) XRF $\mu \mathrm{CT}$ of iron, (c) $\mathrm{XRF} \mu \mathrm{CT}$ of copper, (c) XRF $\mu \mathrm{CT}$ of zinc.

In Figure 13 it can be also observed the 3D visualization of a healthy breast sample. The distribution of iron, copper and zinc in the healthy breast tissue is different and heterogeneity. There are some regions with no concentration of these metals. It can be seen in figure $13 \mathrm{~b}$ that there is no iron in the entire sample but only in a small part of that 
sample. Analysis of healthy and cancer breast sample led us to discovery that the concentration of Fe is bigger in the tumor compared with healthy breast tissues for the same patient (Pereira et al., 2006).

Figure 14 and 15 show the 3D images of lung samples. The figure 14 shows an embryo lung samples and Figure 15 shows an adult lung sample. In these 3D images, it was not possible reconstruct the $3 \mathrm{D} X$-ray transmission tomography because the sample and the attenuation coefficient are very small. On the other hand, it was possible to visualize the $3 \mathrm{D} \mathrm{XRF} \mu \mathrm{CT}$ for the elements iron, copper and zinc.
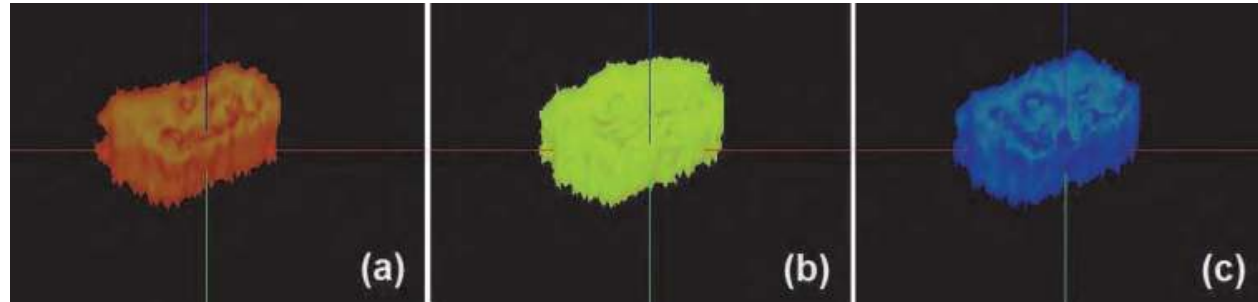

Fig. 14. 3D Tomographic images of an embryo lung samples , (a) XRF $\mu \mathrm{CT}$ of iron , (b) $\mathrm{XRF} \mu \mathrm{CT}$ of copper, (c) $\mathrm{XRF} \mu \mathrm{CT}$ of zinc.
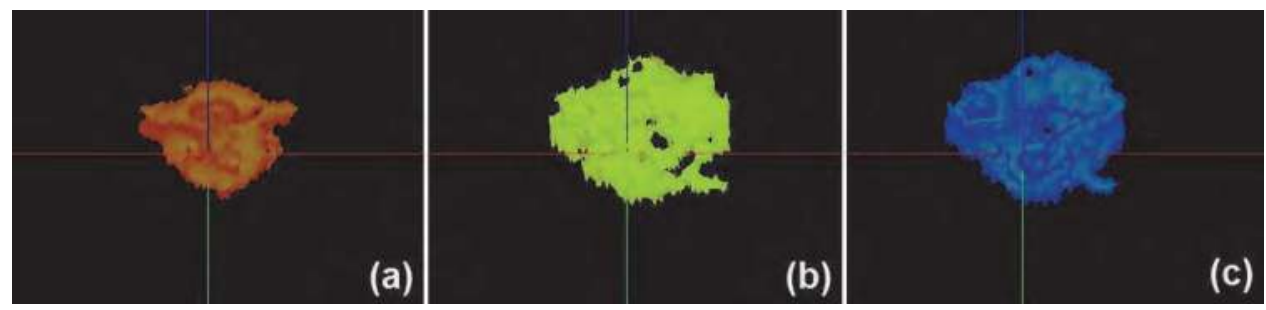

Fig. 15. 3D Tomographic images of an adult lung samples , (a) XRF $\mu \mathrm{CT}$ of iron , (b) XRF $\mu \mathrm{CT}$ of copper, (c) XRF $\mu \mathrm{CT}$ of zinc.

Comparing the elemental distribution images of an embryo and an adult lung, it can be observed that the embryo sample is denser than the adult lung sample. This fact can be explained because the embryo lung was not totally developed.

Although trace elements $\mathrm{Fe}, \mathrm{Cu}$, and $\mathrm{Zn}$ are extremely common, assessment of their amounts is crucial for disease diagnostics. Both excess and deficiency of trace elements have been associated with many diseases including cancer. However, until now, the evidence linking iron, copper and zinc to cancer is far from being conclusive (Rocha et al., 2007) and further research is needed. Using XRF $\mu \mathrm{CT}$ the elemental map can be obtained. Pathologistoncologist cooperation would be most advantageous for future research in this area.

Analyzing the $3 \mathrm{D}$ visualization, it can be observed that the distribution of iron, copper and zinc are different and heterogeneity in those samples. Unfortunately, so far with these samples was not possible to determine the influence of heterogeneous concentrations in the same sample. Greater cooperation with pathologist is required to evaluate these irregular distributions.

The radial streak effects that can be visualized in tomographic reconstructions are because of the low counting statistic in each projection. The images were not processed. 


\section{Conclusion}

$\mathrm{XRF} \mu \mathrm{CT}$ technique has enabled us to determine the elemental distribution of the elements inside of the sample without destroying it. It is a useful tool in qualitative and quantitative analysis of light materials including biological tissues. The great advantage of this technique is the visualization in tree-dimension visualization of the elemental distribution without damaging the material.

The test samples show the viability of X-ray fluorescence microtomography and confirm that this technique can be used to complement other techniques for sample characterization. It is very important to use the algorithm with absorption corrections to get the corrected value of concentration if a quantitative analysis is necessary.

It is necessary to measure more samples and quantify the difference in concentration in one sample and between normal and abnormal tissues to use the X-ray fluorescence microtomography as an analytic tool to analyze biological tissues.

The better definition of the interfaces in X-ray fluorescence images was striking and the spatial resolution of the system can be optimized as a function of the application. In this work, it is used $200 \mu \mathrm{m}$, but it is possible to work with a resolution higher until $20 \mu \mathrm{m}$ using capillary optics. The experimental set up at XRF-LNLS has shown to be very promising and this effort at implementing X-ray fluorescence microtomography was justified by the high quality of the images obtained.

\section{Acknowledgment}

This work was partially supported by National Council for Scientific and Technological Development (CNPq), Research Foundation of the State of Rio de Janeiro (FAPERJ) and Brazilian Synchrotron Light Laboratory(LNLS).

\section{References}

Bernasconi, G. \& Tajani, A. (1996) Quantitative X-Ray Analysis System (QXAS) Software, Package: Documentation Version 1.2. International Atomic Energy Agency, Vienna.

Brunetti, A. \& Golosio, B.(2001). Software for X-ray Fluorescence and scattering Tomographic Reconstruction.Comput. Phys. Commun., Vol. 141(3), pp. 412-425.

Cesareo, R. \& Mascarenhas, S. (1989). A New Tomographic Device Based on the Detection of Fluorescent X-rays. Nuclear Instruments and Methods, Vol. A277, pp. 669-672.

Ebashi S., Koch M. \& Rubenstein E. (1991) Handbook on Synchrotron Radiation, 4 ed., Elsevier Science Publishers.

Geraki K.; Farquarson, M.J.; Bradlet, A. (2004) X-ray Fluorescence and Energy Dispersive X-ray Diffraction for the Quantification of Elemental Concentrations in Breast Tissue, Physics in Medicine and Biology, Vol 49, pp. 1-12.

Golosio, B. et al.(2003). Internal Elemental Microanalysis Combining x-RayFluorescence, Compton and Transmission Tomography, Journal of applied Physics, Vol.94, pp. 145156.

Hogan, J. P. et al. (1991) Fluorescent Computer Tomography: A Model for Correction X-Ray Absorption, IEEE Transactions on Nuclear Science,Vol. 38, pp.1721-1727.

Kak, A. C. \& Slaney,M. (1988) Principles of Computerized Tomographic Imaging, IEEE Press, New York. 
Naghedolfeizi, M. et al. (2003). X-ray Fluorescence microtomography study of Trace elements in a SiC Nuclear Fuel Shell. Journal of Nuclear Materials, Vol. 312, pp. 146155.

Pereira, G. R. et al. (2010). Biological tissues analysis by XRF microtomography. Applied Radiation Isotopes, Vol. 68(4-5), pp. 704-708.

Pereira, G. R. et al. (2009). X-Ray fluorescence microtomography under various excitation conditions. X-Ray Spectrometry, Vol. 38, pp. 244-249.

Pereira, G. R. et al. (2008). Elemental distribution mapping on breast tissue samples. European Journal of Radiology, Vol. 68S, pp. S104-S108.

Pereira, G. R. et al. (2006). Journal of Radioanalytical and Nuclear Chemistry, G. R. et al. (2008). Vol. 269, pp. 469-.

Rocha, H. S. et al. (2007). Diffraction enhanced imaging and X-ray fluorescence microtomography for analyzing biological samples. X-Ray Spectrometry, Vol. 36, pp. 247-253.

Raju, G. J. N. et al. (2006). Trace elemental correlation study in malignant and normal breast tissue by PIXE technique.Nucl. Instr. and Meth. B, Vol. 247, pp. 361-367. 


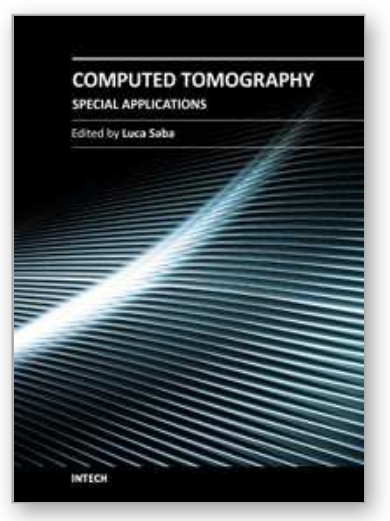

\author{
Computed Tomography - Special Applications \\ Edited by Dr. Luca Saba
}

ISBN 978-953-307-723-9

Hard cover, 318 pages

Publisher InTech

Published online 21, November, 2011

Published in print edition November, 2011

CT has evolved into an indispensable imaging method in clinical routine. The first generation of CT scanners developed in the 1970s and numerous innovations have improved the utility and application field of the CT, such as the introduction of helical systems that allowed the development of the "volumetric CT" concept. Recently interesting technical, anthropomorphic, forensic and archeological as well as paleontological applications of computed tomography have been developed. These applications further strengthen the method as a generic diagnostic tool for non destructive material testing and three dimensional visualization beyond its medical use.

\title{
How to reference
}

In order to correctly reference this scholarly work, feel free to copy and paste the following:

Gabriela R. Pereira and Ricardo T. Lopes (2011). X-Ray Fluorescence Microtomography in Biological Applications, Computed Tomography - Special Applications, Dr. Luca Saba (Ed.), ISBN: 978-953-307-723-9, InTech, Available from: http://www.intechopen.com/books/computed-tomography-special-applications/x-rayfluorescence-microtomography-in-biological-applications

\section{INTECH}

open science | open minds

\section{InTech Europe}

University Campus STeP Ri

Slavka Krautzeka 83/A

51000 Rijeka, Croatia

Phone: +385 (51) 770447

Fax: +385 (51) 686166

www.intechopen.com

\section{InTech China}

Unit 405, Office Block, Hotel Equatorial Shanghai

No.65, Yan An Road (West), Shanghai, 200040, China 中国上海市延安西路65号上海国际贵都大饭店办公楼 405 单元

Phone: $+86-21-62489820$

Fax: +86-21-62489821 
(C) 2011 The Author(s). Licensee IntechOpen. This is an open access article distributed under the terms of the Creative Commons Attribution 3.0 License, which permits unrestricted use, distribution, and reproduction in any medium, provided the original work is properly cited. 